\title{
MINAT GENERASI MUDA PROVINSI NARATHIWAT THAILAND SELATAN TERHADAP BIDANG PERTANIAN
}

\section{Interest Of Youth Generation Province Narathiwat South Thailand On Agriculture}

\author{
Mohamad Rifqi Fauzi'1), Reny Sukmawani2), Endang Tri Astutiningsih ${ }^{3)}$ \\ ${ }_{1}^{1}$ Program Studi Agribisnis, Fakultas Pertanian, Universitas Muhamadiyah \\ Sukabumi. Email : ikiiki3362@gmail.com \\ ${ }^{2}$ Program Studi Agribisnis, Fakultas Pertanian, Universitas Muhamadiyah \\ Sukabumi. Email : renysukmawani@ummi.ac.id \\ ${ }^{3}$ Program Studi Agribisnis, Fakultas Pertanian, Universitas Muhamadiyah \\ Sukabumi.Email : end.end2016@ummi.ac.id
}

\begin{abstract}
ABSTRAK
Penelitian ini bertujuan untuk mengetahui minat generasi muda Provinsi Narathiwat Thailand Selatan di sektor pertanian dengan menggunakan metode analisis deskriptif. Hasil penelitian menunjukan bahwa minat generasi muda di Provinsi Narathiwat Thailand selatan terhadap sektor pertanian sangat tinggi. Indikator yang mendorong rasa minat dari yang tertinggi hingga terendah adalah rasa senang, rasa bangga, rasa memilih yang diminati dan rasa penting terhadap bidang pertanian.
\end{abstract}

Kata Kunci: Minat, Generasi Muda, Pertanian

\begin{abstract}
The aim of this study is to find out the interest of the young generation of Southern Thailand's Narathiwat Province in the sector of agriculture using descriptive analysis methods. The results of the study shows that the interest of the young generation in southern Thailand's Narathiwat Province on the sector of agriculture is very high. The indicators that encourage a sense of interest from the highest to the lowest are pleasure, pride, a sense of choice that is desirable and an important sense of agriculture.
\end{abstract}

Keywords: Interest, Youth, Agriculture 


\section{PENDAHULUAN}

Pertanian adalah kegiatan pemanfaatan sumberdaya hayati yang dilakukan manusia untuk menghasilkan bahan pangan, bahan baku industri atau sumber energi, serta untuk mengelola lingkungan hidupnya. Berdasarkan definisi tersebut maka dapat disimpulkan bahwa yang mencakup bidang pertanian adalah tumbuhan, pertenakan, dan perikanan (Kementrian Pertanian, 2017). Dengan demikian bidang pertanian cukup penting karena produk yang dihasilkannya sangat dibutuhkan oleh semua orang dari mulai kebutuhan primer, sekunder dan tersier. Walaupun bidang pertanian sangat penting dan dibutuhkan, kenyataan di lapangan minat generasi muda untuk menekuni bidang ini sangat kurang. Hal ini dibuktikan dengan hasil kajian dari Losvitasari (2017) yang menyimpulkan bahwa generasi muda di Subak Gadon III Braban, Tabanan tidak memiliki minat di bidang pertanian. Hasil kajian ini diperkuat oleh pernyataan Lembaga Ilmu Pengetahuan Indonesia (2015) bahwa para pemuda mengalami perubahan persepsi seiring arus modernisasi sehingga menjadi petani tidak lagi menjadi pilihan mereka. Padahal Indonesia membutuhkan petani-petani yang produktif untuk memaksimalkan produksi pangan, terutama Indonesia adalah negara agraris. Kondisi ini hampir sama di seluruh wilayah Indonesia, padahal bidang pertanian sampai kapanpun akan tetap diperlukan. Sehingga harus menjadi perhatian karena apabila dibiarkan akan berdampak pada ketahanan pangan. Salah satu dampaknya adalah akan meningkatkan ketergantungan pada negara lain dalam penyediaan kebutuhan pokok yang bersumber dari hasil pertanian. Selama ini beberapa produk pertanian diimpor dari negara lain. salah satunya dari negara Thailand selalu impor seperti beras, buah-buahan, biji-biji, karet, gula dan ikan (Kementrian Pertanian, 2017).

Fenomena ini diperkuat lagi oleh kajian FAO (2014) yang menyatakan bahwa para pemuda perdesaan menghadapi banyak rintangan dalam upaya mencari nafkah. Kaum muda sering juga kekurangan akses kredit dan banyak lainnya sumber daya produktif yang diperlukan untuk pertanian. Hal ini tentu semakin mengurangi minat kaum muda terhadap pertanian.

Menurut Budiarto (2016) Thailand adalah Negara yang memiliki sistem pertanian yang baik di dunia dan pengekspor terbesar di dunia. Thailand cukup dikenal karena produk pertaniannya. Hampir semua produk pertanian di Indonesia dengan kualitas baik selalu disebut sebagai produk Bangkok (contoh: ayam Bangkok, Papaya Bangkok, Jambu Bangkok, dan Beras yang berkualitas baik). Reputasi Thailand sebagai penghasil produk pertanian yang baik dapat dipastikan, dan didukung oleh sumber daya manusia (SDM) yang baik.

Hal ini bertolak belakang dengan hasil penelitian Losvitasari (2017) menyimpulkan bahwa generasi muda di Thailand Selatan tidak memiliki minat di bidang pertanian. Sehingga memengaruhi terhadap jumlah petani di Thailand, oleh sebab itu penelitian ini difokuskan untuk mengkaji lebih jauh lagi tentang 
bagaimana minat generasi muda dibidang pertanian, khususnya di Provinsi Narathiwat Thailand Selatan dengan potensi yang cukup baik dalam bidang pertanian.

\section{METODOLOGI}

\section{Lokasi dan Waktu Penelitian}

Lokasi penelitian di Provinsi Narathiwat Thailand Selatan dari bulan November sampai dengan April 2019.

\section{Metode Analisis}

Metode yang digunakan dalam penelitian ini adalah metode deskriptif. Menurut Nazir (2014), metode deskriptif merupakan metode yang digunakan dalam penelitian untuk membuat gambaran situasi atau kejadian yang teliti. Teknik penelitian yang digunakan adalah metode survey. Metode survey digunakan untuk mendapatkan data dari tempat tertentu, data tersebut didapatkan dari penyebaran kuesioner, test, wawancara terstruktur sebagai alat bantu dalam mengumpulkan data penelitian (Sugiono, 2009).

Sumber data yang digunakan adalah data primer yang didapati dari wawancara dengan menggunakan kuisioner. Dan sumber data sekunder diperoleh dari studi pustaka seperti kondisi wilayah, jurnal, text book, penelitian sebelumnya yang menunjang lokasi. Lokasi penelitian di Provinsi Narathiwat Thailand Selatan dengan jumlah responden sebanyak 20 Orang ditentukan dengan metode Simple Random Sampling.

\section{HASIL DAN PEMBAHASAN}

Karakteristik responden dalam penelitian sangat penting. Karakteristik responden dapat menggambarkan profil responden. Karakteristik responden dalam memilih ini meliputi memilih usia, jenis kelamin, pendidikan. Karakteristik responden ini dapat memengaruhi keputusan pemuda di provinsi Narathiwat dalam memilih minat atau tidak minatnya terhadap bidang pertanian.

1) Responden Berdasarkan Usia

Analisis responden berdasarkan usia ini bertujuan untuk membedakan usia minat dalam bidang pertanian karena perbedaan usia juga dapat berpengaruh terhadap minat dalam bidang pertanian. Jumlah responden berdasarkan tingkat usia dapat di lihat pada tabel. 
Tabel 1. Responden berdasarkan Usia

\begin{tabular}{|c|c|c|c|}
\hline No. & Jenjang Usia (Tahun) & Jumlah Responden (Orang) & Persentase (\%) \\
\hline 1 & $13-16$ & 3 & 24 \\
\hline 2 & $16-19$ & 5 & 36 \\
\hline 3 & $19-25$ & 12 & 40 \\
\hline \multicolumn{2}{|r|}{ Total } & 20 & 100 \\
\hline
\end{tabular}

Pada Tabel 1, menunjukan responden yang paling banyak minat generasi muda Thailand terhadap bidang Pertanian berdasarkan karateristik usia. 24 persen berusia 13-16 tahun, disusul pada usia 16-19 tahun lalu sebesar 36 persen, pada usia kurang dari 25 tahun dan sebesar 40 persen berusia 19-25 tahun. Hal ini menunjukan dominan responden yang berusia 19-25 tahun.

\section{Responden Berdasakan Jenis Kelamin}

Jenis kelamin ini merupakan salah satu faktor yang berpengaruh pada keputusan minat bekerja di bidang pertanian adalah jenis kelamin. Tabel berikut responden berdasarkan jenis kelamin dapat dilihat pada tabel berikut :

Tabel 2. Responden Berdasarkan Jenis Kelamin

\begin{tabular}{cccc}
\hline No. & Jenis Kelamin & Jumlah Responden (Orang) & Persentase (\%) \\
\hline 1 & Laki-laki & 8 & 40 \\
2 & Perempuan & 12 & 60 \\
\hline & Total & $\mathbf{2 0}$ & $\mathbf{1 0 0}$ \\
\hline
\end{tabular}

Pada Tabel 2, menunjukan responden yang paling banyak minat generasi muda Thailand terhadap bidang Pertanian berdasarkan karateristik Jenis Kelamin. 40 persen laki-laki dan responden perempuan sebesar 60 persen. Hal ini menunjukan bahwa dominan responden berjenis kelamin laki - laki.

\section{Responden Berdasarkan Pendidikan}

Responden dalam melihat ini berdasarkan tingkat pendidikan tertinggi dalam tiga jenis diantaranya di dalam minat generasi muda provinsi Narathiwat Thailand Selatan terhadap bidang pertanian dikategorikan SMP, SMA dan D3.

Tabe1 3. Responden Berdasarkan Pendidikan

\begin{tabular}{clcc}
\hline No. & Tingkat Pendidikan & Jumlah Responden (Orang) & Persentase (\%) \\
\hline 1 & SMP & 3 & 24 \\
2 & SMA & 5 & 36 \\
3 & D3 & 12 & 40 \\
\hline \multicolumn{2}{r}{ Total } & $\mathbf{2 0}$ & $\mathbf{1 0 0}$ \\
\hline
\end{tabular}

Pada Tabel 3, menunjukan responden sebagian besar memilih tingkat pendidikan D3 sebesar 40 persen. Hal ini menunjukan bahwa dominan responden terhadap bidang pertanian terbanyak yaitu dari jenjang tingkatan D3. 


\section{Minat Responden Terhadap Bidang Pertanian}

Minat merupakan sebuah aspek kunci terhadap kesesuaian antara seseorang dan pekerjaan, menjadikan suatu alasan mengapa para petani padi sawah masih tetap bertahan dengan usahatani yang dijalankannya. Menurut Khairana (2011) bahwa bentuk minat seseorang dipengaruhi oleh latar belakang orangtua, lingkungan, tingkat ekonomi, status sosial, dan pengalaman.

Generasi muda adalah generasi penerus bangsa, generasi yang baik akan menghasilkan bangsa yang baik pula. Perkembangan jaman yang sudah semakin maju ini akan memengaruhi kehidupan penerus generasi khususnya di Provinsi Narathiwat Thailand Selatan. Berbekal pendidikan yang baik maka para remaja dapat melanjutkan kehidupan yang baik pula. Berdasarkan data reponden minat generasi muda Provinsi Narathiwat Thailand Selatan menunjukan bahwa sebagian besar responden berpendidikan sekolah tinggi, yaitu sebanyak 12 orang responden (40 persen) lebih banyak daripada tingkat menengah atas dan tingkat menengah pertama. Dari data tersebut menunjukan bahwa minat generasi muda Provinsi Narathiwat Thailand Selatan lebih diminati di tingkat sekolah tinggi. Hasil pengolahan data terhadap minat generasi muda secara rinci tercantum dalam tabel di bawah ini.

Tabel 4. Minat Generasi Muda

\begin{tabular}{clcc}
\hline \multirow{2}{*}{ Skor } & \multirow{2}{*}{ Kriteria } & \multicolumn{2}{c}{ Responden } \\
\cline { 3 - 4 } & Tidak Minat & Jumlah & Persentase (\%) \\
\hline $1-2$ & Kurang Minat & 2 & 0 \\
$2-3$ & Minat & 0 & 10 \\
$3-4$ & Sangat Minat & 18 & 0 \\
$4-5$ & & & 90 \\
\hline
\end{tabular}

Dari tabel di atas dillihat bahwa 90 persen responden sangat minat terhadap bidang pertanian dan 10 persen kurang minat terhadap bidang pertanian karena memiliki skor 2-3. Dari 18 responden yang sangat minat terhadap bidang pertanian ternyata memiliki orang tua bekerja disektor pertanian. Tabel dibawah ini menggambarkan nilai indikator yang dominan yang memengaruhi besarnya minat responden terhadap bidang pertanian.

Tabel 5. Tingkat Minat Responden Berdasarkan Skoring

\begin{tabular}{|c|c|c|c|c|c|c|c|}
\hline \multirow{2}{*}{ Indikator } & \multicolumn{6}{|c|}{ Skor } & \multirow{2}{*}{$\begin{array}{l}\text { Rata- } \\
\text { Rata }\end{array}$} \\
\hline & 1 & 2 & 3 & 4 & 5 & $\mathbf{N}$ & \\
\hline 1. Rasa Penting & & & 7 & 1 & 10 & 18 & 2,7 \\
\hline 2. Rasa Senang & & & 1 & & 17 & 18 & 4,9 \\
\hline 3. Kebanggaan & & & & 3 & 15 & 18 & 4,8 \\
\hline $\begin{array}{l}\text { 4. Memilih yang diminati dibanding } \\
\text { yang lain }\end{array}$ & & & & 4 & 14 & 18 & 4,7 \\
\hline
\end{tabular}


Berdasarkan Tabel 5 diatas dapat dilihat bahwa responden yang sangat minat terhadap bidang pertanian sebagian besar karena memiliki rasa senang terhadap bidang pertanian, maka urutan indikator yang memengaruhi rasa minat responden adalah rasa senang, rasa bangga, memilih yang diminati dibanding yang lain dan rasa penting. Dari hasil ini menunjukan bahwa sudah ada pada generasi muda rasa senang terhadap bidang pertanian dan perlu ada upaya lebih kuat dari beberapa pihak untuk memunculkan rasa ini menjadi rasa bangga dan bahkan memilih sektor pertanian dibandingkan dengan sektor yang lain.

\section{KESIMPULAN DAN REKOMENDASI KEBIJAKAN}

Kesimpulan yang dapat ditarik dalam hasil penelitian menunjukan bahwa minat generasi muda di Provinsi Narathiwat Thailand selatan terhadap bidang pertanian sangat tinggi. Indikator yang mendorong rasa minat dari yang tertinggi hingga terendah adalah rasa senang, rasa bangga, rasa memilih yang diminati dan rasa penting terhadap bidang pertanian. Meningkatkan minat generasi muda Provinsi Narathiwat Thailand Selatan dalam bidang pertanian salah satunya dengan pelatihan di setiap sekolah atau setiap wilayah dan juga pengenalan teknologi inovasi karena mereka butuh wawasan yang baru untuk diberikan kepada generasi muda Provinsi Narathiwat Thailand Selatan. Untuk memperluas rasa minat generasi muda Provinsi Narathiwat perlu ada informasi teruntuk orang-orang yang berminat dibidang pertanian.

\section{DAFTAR PUSTAKA}

Kementrian pertanian. 2017. Budidaya Tanaman Padi. Penerbit Kanisius. Yogyakarta.

Losvitasari. Ni Made 2017.

http://indoagribisnis.wordpress.com/2008/09/21/potensi-agribisnis-

indonesia/ Diakses 17 Juli 2013.

Pernyataan lembaga ilmu pengetahuan indonesia. 2015. Manajemen Strategi

Pengembangan Koperasi Petani Organik Serikat Petani Indonesia di Bogor

[Skripsi]. Bogor. Fakultas Pertanian, Institut Pertanian Bogor.

Fao. 2014. Budidaya Padi Secara Organik. Cetakan 4. Penebar Swadaya. Jakarta.

A Budiarto,. 2016. Pertanian Organik dan Revitalisasi Pertanian.

http://goorganik.com/mod.php? $\bmod =$ publisher\&op=viewarticle\&cid=6 \&artid=9. [20 April 2013].

Sugiono, 2009. Metode penelitian kualitatif dan kuantitatif [Skripsi]. Bogor. Fakultas Pertanian. Institut Pertanian Bogor. 
Nazir. 2014. Metode penelitian . [Skripsi]. Bogor. Fakultas Ekonomi dan Manajemen, Institut Pertanian Bogor.

Khairina, (2011) Pengaruh Eksistensi Bank Mini Terhadap Minat Menabung Siswa Jurusan Akuntansi Di Sekolah Menengah Kejuruan Negeri 1 Pekanbaru. Skripsi thesis, Universitas Islam Negeri Sultan Syarif Kasim Riau.

Kantor statistika nasional. 2017. Geografi wilayah Thailand . Penerbit: Nasional Thailand. 